\title{
Assessment of Motor Performances in Italian Primary School Children: Results of SBAM Project
}

\author{
Dario Colella1, Domenico Monacis ${ }^{1,2}$, Fabio Massari1 \\ ${ }^{1}$ Department of Clinical and Experimental Medicine, University of Foggia, Foggia, Italy \\ ${ }^{2}$ Department of Humanities, Cultural Heritage, Education Sciences, University of Foggia, Foggia, Italy \\ Email: dario.colella@unifg.it, domenico.monacis@unifg.it
}

How to cite this paper: Colella, D., Monacis, D., \& Massari, F. (2019). Assessment of Motor Performances in Italian Primary School Children: Results of SBAM Project. Advances in Physical Education, 9, 117-128. https://doi.org/10.4236/ape.2019.92009

Received: March 27, 2019

Accepted: May 6, 2019

Published: May 9, 2019

Copyright $\odot 2019$ by author(s) and Scientific Research Publishing Inc. This work is licensed under the Creative Commons Attribution International License (CC BY 4.0).

http://creativecommons.org/licenses/by/4.0/

\begin{abstract}
The aim of this study was to present the results of the triennial SBAM regional program aimed at monitoring 8-year old children in the Apulian region of Southern Italy from 2013 to 2016. The program included at launch 17,102 children in the first year, 16,104 children in the second year and 14,847 children in the third year. The sample who completed the monitoring was less than the number of children recruited for organizational and didactic reasons $(\mathrm{N}=15,231, \mathrm{~N}=14,147$ and $\mathrm{N}=13,362)$. SBAM was a multi-component program and included different integrated action plans: physical education, active transport (pedibus), and methods for developing healthy eating habits. For each year, four motor tests (long jump standing, shuttle run, 6 min walk test, and medicine ball throw), a motor coordination test and two self-reports for evaluating self-efficacy and enjoyment were proposed to all children. The results showed gender and group differences (normal-weight vs. overweight-obese) in both motor tests and self-reports $(p<0.05)$. The annual results of the motor tests were sorted in deciles in order to have a regional observation and monitoring database concerning the motor development skills among children and preadolescents. Boys showed motor performance, perceived self-efficacy scores and enjoyment higher than females in three years. Growth influences the development of motor abilities; overweight and obese males and females showed a different development of motor performance that was lower than in children with a BMI in the norm. It is necessary to develop physical education in primary school, increasing opportunities and adapting them to the needs of all children. SBAM project highlighted the need to promote interdisciplinary and inter-institutional actions to promote child health and acquire physically active lifestyles.
\end{abstract}




\section{Keywords}

Health Promotion, Motor Development, Physical Self-Efficacy, Physical Education, Primary School

\section{Introduction}

Teaching physical education in primary school is a disciplinary area in which the motor skills learning and the interdisciplinary and transversal objectives related to correct eating habits and healthy lifestyles flow together. Numerous studies and good practices show the effects of motor activities for the prevention of various diseases in the developmental age (obesity, diabetes, heart disease) and the promotion of correct lifestyles, through multi-component and inter-institutional interventions at school, sport centres and local organizations (Hills, Dengel, \& Lubans, 2015). Physical education in primary school is the first structured setting for developing semantic and logical connections with other disciplines and learning. Motor and physical activities can contribute significantly to the educational process of the person. Motor experience can provide quanti-qualitative opportunities to be physically active, in which the students are fully involved not only on the physical-motor level but also cognitive, emotional and social one (Ciotto \& Fede, 2014; Beets et al., 2016). Recent studies conducted in the school setting, have investigated the relationships between specific organizational modalities of motor activities and cognitive development., with a special emphasis on cognitive functions (Pesce et al., 2009), the relation among different types of motor and sport activities (such as dance, sports games, outdoor education), academic performance, the increase in levels of daily physical activity (according to quantity-duration, intensity, difficulty) and the learning of motor skills (Singh, 2012; Lubans et al., 2016; Hillman \& Biggan, 2017).

Sedentary habits during developmental age depend on various socio-cultural factors, responsible for the low levels of physical activity and the increase of overweight and obesity (Ekelund, 2012). The recommendation of the Council of European Union warns that the benefits of physical activity in the early age concern the decreased risk of cardiovascular diseases, some types of cancer, diabetes, the improvement of musculoskeletal efficiency and the control of body weight, as well as the benefits on cognitive processes (Council of European Union, 2013). The European Council Document (Council of European Union, 2013) specifies that physical education at school is an unavoidable opportunity to raise HEPA awareness (health-enhancing physical activity) and implement prevention programs and health promotion.

The SBAM Program! took place in Apulia region, in the South of Italy, from 2013 to 2016. SBAM! is a three-year, inter-institutional and multi-component program, composed of different and complementary measures, based on curricular physical education, correct eating habits and active transport through pe- 
dibus. The program was structured to implement measures to reduce sedentary habits and prevent childhood overweight and obesity. The implementation of SBAM! was an important challenge for the teaching organization of the participating schools. Principals and teachers requested to integrate the presence of experts outside the school, even if in different periods and operating phases. The intervention components include teachers training and parent engagement. The program proposed to induce changes in children's behavior, promoting in the "school" setting, correct food choices and active lifestyle.

Main purposes: promoting correct eating habits and children's awareness of food choice and consumption; motor skills learning during curricular physical education lessons; developing active transport through pedibus, promoting recreative sport and socialization through fair play; promoting active lifestyles to reduce sedentary habits and support physical activity during leisure time; preparing safe routes for the home-school journey (Colella, 2014).

Motor development during the developmental age depends on and is influenced by the growth and organic maturation of the child and the interaction with the environment in which he grew up (Malina, 2004). The opportunities and environmental conditions interact with the biological substrates of growth and maturation and determine the child motor skills' repertoire. Motor development is a continuously changing process that involves various factors: 1) neuromuscular maturation; 2) physical growth and child's behavioral characteristics; 3) time of physical growth, biological maturation and behavioral development; 4) the effects of previous motor experiences; 5) new motor experiences (Rauner, Mess, \& Woll, 2013). Several studies have showed inverse relationships between physical efficiency and overweight. Rauner et al. (2013) analyzing the relationship between physical activity, fitness and overweight/obesity, highlight that obesity was inversely related to physical activity. Mediation effects in the relationship between BMI, fitness and physical activity have been detected. Excessive body weight would be the cause or effect of low levels of physical activity and low levels of fitness. According to Cattuzzo et al. (2016) the learning and development of motor skills can increase physical fitness levels, directly and indirectly, and promote long-term health in children and adolescents.

\section{Methods}

\subsection{Objective}

The aim of this study was to evaluate and compare motor abilities (strength, resistance, motor coordination) and the factors of perceived self-efficacy and enjoyment, according to gender and group differences (body mass index).

\subsection{Participants and Setting}

Sbam! (Health Wellness Food Movement at school) was a multi-component regional project aimed at primary schools in Apulia Region, in the south of Italy. The project has been promoted and financed by the Regional Administration 
and had provided for the collaboration of the University of Foggia, the CONI (Puglia regional committee) and local health authorities. The three-year didactic interventions involved a sample of children from the third to the fifth class. The schools $(\mathrm{N}=207)$ responded to an invitation from the Regional Administration and involved all their third year classes. The aim of this project is to induce changes in children's behavior, supporting and promoting, in the school context, correct food choice and a healthy physically active lifestyle. The launch of the program included the following phases: 1) communication to primary schools in the region for the identification of class groups and referent teachers; 2) recruitment of experts (specialist teacher) by CONI Puglia; 3) training meeting with generalist teachers; 4) communication and meetings with families; 5) selection and training of physical education special teachers; 6) practical implementation of the project according to a shared time schedule; 7) motor monitoring and psychological related factors. Physical education lessons at primary schools were conducted by experts and in each lesson the generalist teacher/class teacher was present for educational and regulatory reasons. Each expert has joined the generalist teacher carrying out 20 hours of teaching activity for each class group (1 hour per week from January to May 2013): in the last 3 lessons the integrated assessment was carried out into didactic process in the gym. Motor monitoring included both the detection of BMI and the detection of data concerning motor development and the evaluation perceived self-efficacy and liking for motor activities.

\subsection{Procedure}

The anthropometric data (height and weight) and those relating to motor development and psychological factors (physical self-efficacy and enjoyment) were carried out. The sample that carried out the tests of the monitoring (Table 1) was less than the number of children recruited $(17,102$ children in the first year, 16,104 children in the second year and 14,847 children in the third year) for organizational and didactic reasons, for example: 1) children absent on days scheduled for motor assessment and for whom recovery was not possible; 2) errors in data collection and in the tabulation process; 3 ) incomplete tabulated data.

According to Cole et al., (2000) participants were divided by gender and group differences: normal-weight $(\mathrm{Nw})$, overweight $(\mathrm{Ow})$ and obese $(\mathrm{Ob})$ children (Cole, 2000). The following motor tests were assessed (Ruiz et al., 2010): long jump standing (SLJ) and medicine ball throw (MBT) to evaluate strength of the lower and upper limbs, shuttle run $10 \times 4(10 \times 4)$ and 6 min walk test $(6 \mathrm{~min}$

Table 1. Monitoring sample description.

\begin{tabular}{cccc}
\hline Gender & 1 year (age 8 \pm 0) & 2 year (age 9 \pm 0) & 3 year (age 10 \pm 0) \\
\hline Male $(\mathrm{N}=)$ & 7901 & 7317 & 6427 \\
Female $(\mathrm{N}=)$ & 7330 & 6830 & 6935 \\
Total & 15,231 & 14,147 & 13,362 \\
\hline
\end{tabular}


WT) to evaluate resistance, while fundamental movement skills (rolling, running, jumping, throwing, grasping) were evaluated through the coordination tasks. The deciles were used for each test. In this way the distribution was divided for ten instead of 100 The minimum value is that value which has above $100 \%$ of the observed cases; the first decile is that value which has below $10 \%$ of the analyzed subjects and $90 \%$ above; the second decile is the value that has below $20 \%$ of the observed subjects and above $80 \%$, and so on. The tenth decile corresponds to the maximum and has $100 \%$ of the cases below.

Two self-reports were also utilized: the PSP_C (Colella et al., 2008) and the PACES (Carraro, Young, \& Robazza, 2008) to measure enjoyment. Enjoyment of PA was assessed using the Physical Activity Enjoyment Scale (PACES), (Carraro, Young, \& Robazza, 2008). The 16-item scale is scored on a 5-point Likert scales, with responses ranging from 1 (Disagree a lot) to 5 (Agree a lot). A high score on the positive scale (PACES_P) and a low score on the negative (PACES_N) indicate a high pleasure in physical activity. A total score can also be calculated, reversing the scores of the negative items and adding them to the positive ones, with this procedure the total score of the PACES can vary between 16 and 80 points.

The PSP_C (Physical Self Efficacy Scale for Children) utilizes six items representing strength, speed, and coordinative abilities. The items are structured in response scales having a 1- to 4-point format. Children are required to think of themselves when playing, performing physical education exercises, or when involved in sporting activities. For each item, participants are asked to choose one of the four sentences best representing their personal feelings. Therefore, the total test score can range from 1 to 24 . High scores would indicate a high self-perception of physical ability, whereas low scores would reflect a low self-perception.

Each group-class took between 20 and 30 hours of physical education with a specialist teacher (Expert) who supported the generalist teacher. The motor assessment protocol was proposed two months after the project started (April 2013).

\section{Results}

In addition to the descriptive statistics $(\mathrm{M} \pm \mathrm{SD})$, analysis of the variance ANOVA 3 (group, normal-weight vs overweight vs obese) $\times 2$ (gender) was performed, to highlight significant differences in relation to the dependent variables considered. The significance index was set at $p<0.05$. Results showed significant values for motor tests (long jump standing, shuttle run, 6 min walk test and medicine ball throw) and the coordination tasks in relation to BMI and gender difference $(p<0.05)$.

However, the following results can be highlighted. BMI values have not improved over the three-year period, regardless of gender and age difference: data showed a non-significant increase in BMI from 2013 to 2015. The results of all motor test (Table 2$)$ highlight an evolution of the performances $(p<0.05)$ during 
Table 2. Motor test measures divided by BMI cutoff and years.

\begin{tabular}{|c|c|c|c|c|c|c|c|c|c|c|}
\hline \multicolumn{11}{|c|}{ 1st year-2013/2014 } \\
\hline \multirow[t]{2}{*}{ BMI cut off } & \multicolumn{2}{|c|}{ SLJ } & \multicolumn{2}{|c|}{ MBT } & \multicolumn{2}{|c|}{$10 \times 4$} & \multicolumn{2}{|c|}{$6 \mathrm{wt}$} & \multicolumn{2}{|c|}{ Motor coordination (s) } \\
\hline & M & $\mathrm{SD}$ & M & $\mathrm{SD}$ & M & $\mathrm{SD}$ & M & $\mathrm{SD}$ & M & SD \\
\hline $\mathrm{Nw}$ & 1.16 & 0.24 & 3.63 & 0.92 & 14.53 & 2.14 & 566.32 & 154.56 & 25.59 & 6.51 \\
\hline Ow & 1.09 & 0.22 & 3.83 & 0.93 & 14.84 & 2.19 & 554.67 & 147.88 & 26.12 & 6.03 \\
\hline $\mathrm{Ob}$ & 1.02 & 0.22 & 4.01 & 1.21 & 15.31 & 2.14 & 546.48 & 149.46 & 27.01 & 6.24 \\
\hline \multicolumn{11}{|c|}{ 2nd year-2014/2015 } \\
\hline BMI cut off & \multicolumn{2}{|c|}{ SLJ } & \multicolumn{2}{|c|}{ MBT } & \multicolumn{2}{|c|}{$10 \times 4$} & \multicolumn{2}{|c|}{$6 w t$} & \multicolumn{2}{|c|}{ Motor coordination (s) } \\
\hline & M & SD & M & $\mathrm{SD}$ & M & $\mathrm{SD}$ & M & SD & M & SD \\
\hline $\mathrm{Nw}$ & 1.25 & 0.25 & 4.27 & 1.10 & 13.55 & 2.01 & 635.22 & 156.48 & 23.39 & 5.54 \\
\hline Ow & 1.17 & 0.24 & 4.65 & 1.13 & 14.04 & 2.22 & 627.07 & 118.27 & 24.32 & 5.35 \\
\hline $\mathrm{Ob}$ & 1.08 & 0.23 & 4.83 & 1.19 & 14.71 & 2.48 & 604.38 & 120.37 & 25.44 & 7.30 \\
\hline \multicolumn{11}{|c|}{3 rd year-2015/2016 } \\
\hline \multirow[t]{2}{*}{ BMI cut off } & \multicolumn{2}{|c|}{ SLJ } & \multicolumn{2}{|c|}{ MBT } & \multicolumn{2}{|c|}{$10 \times 4$} & \multicolumn{2}{|c|}{$6 \mathrm{wt}$} & \multicolumn{2}{|c|}{ Motor coordination (s) } \\
\hline & M & SD & M & $\mathrm{SD}$ & M & $\mathrm{SD}$ & M & $\mathrm{SD}$ & M & SD \\
\hline $\mathrm{Nw}$ & 1.30 & 0.34 & 5.02 & 1.27 & 13.23 & 1.68 & 657.98 & 141.03 & 21.25 & 4.27 \\
\hline Ow & 1.21 & 0.33 & 5.26 & 1.29 & 13.63 & 1.74 & 664.66 & 128.67 & 22.05 & 4.32 \\
\hline $\mathrm{Ob}$ & 1.12 & 0.28 & 5.32 & 1.36 & 14.26 & 2.14 & 643.03 & 125.92 & 23.49 & 5.01 \\
\hline
\end{tabular}

Note: $\mathrm{Nw}$ refers to normal weight, $\mathrm{Ow}$ to overweight and $\mathrm{Ob}$ to obese children. SLJ stands for Standing Long Jump, MBT for Medicine Ball Throw, $10 \times 4$ for Shuttle Run Test, $6 \mathrm{wt}$ for 6 Minutes Walking Test.

the three-years period (sample overall). This is mainly due to the process of organic maturation and physical growth, but also to the processes of motor learning and motor coordination, due to the increase in motor experiences. The motor performances of normal-weight group (both male and female) are better than the overweight and obese group, regardless of years difference (Table 2). Only in the MBT the normal-weight group shows lower performances compared to the overweight and obese group, expression of a greater strength.

Questionnaires underline how BMI influences psychological factors (perceived self-efficacy and enjoyment). The results of the PSP_C (physical self-efficacy) questionnaire showed differences according to the school year factor: the results of the second year were better than those of the first but lower than those of the third. Likewise, data relating to the PACES self-report (enjoyment) evidence significant differences in the three school years (Table 3): the values of the negative scale indicate a gradual reduction in the three-year period. Males in normal weight always showed higher scores $(p<0.05)$ both in perceived self-efficacy and in positive emotions (Positive scale of the PACES questionnaire) than the overweight and obese ones.

Table 4 \& Table 5 show the deciles, divided by gender and related to the last year of monitoring (2015/2016). The fifth decile corresponds to the median and 
Table 3. Self-efficacy and Enjoyment, (Paces_P e Paces_N) for BMI cut off and year.

\begin{tabular}{|c|c|c|c|c|c|c|}
\hline \multicolumn{7}{|c|}{ 1st year-2013/2014 } \\
\hline \multirow[t]{2}{*}{ BMI cut off } & \multicolumn{2}{|c|}{ PSP_C } & \multicolumn{2}{|c|}{ Paces_P } & \multicolumn{2}{|c|}{ Paces_N } \\
\hline & $\mathbf{M}$ & SD & M & SD & $\mathbf{M}$ & SD \\
\hline $\mathrm{Nw}$ & 17.33 & 2.91 & 37.54 & 5.19 & 12.11 & 4.33 \\
\hline Ow & 17.24 & 2.81 & 37.57 & 5.15 & 12.39 & 4.41 \\
\hline \multirow[t]{2}{*}{$\mathrm{Ob}$} & 16.80 & 2.82 & 37.26 & 5.2 & 12.79 & 4.32 \\
\hline & \multicolumn{4}{|c|}{ 2nd year-2014/2015 } & & \\
\hline \multirow[t]{2}{*}{ BMI cut off } & \multicolumn{2}{|c|}{ PSP_C } & \multicolumn{2}{|c|}{ Paces_P } & \multicolumn{2}{|c|}{ Paces_N } \\
\hline & $\mathbf{M}$ & SD & $\mathbf{M}$ & SD & $\mathbf{M}$ & SD \\
\hline $\mathrm{Nw}$ & 19.26 & 3.28 & 39.94 & 6.43 & 9.06 & 3.73 \\
\hline Ow & 18.97 & 3.36 & 39.83 & 6.78 & 9.08 & 3.69 \\
\hline \multirow[t]{2}{*}{$\mathrm{Ob}$} & 18.35 & 3.18 & 39.53 & 6.67 & 9.18 & 3.84 \\
\hline & \multicolumn{4}{|c|}{ 3rd year-2015/2016 } & & \\
\hline \multirow[t]{2}{*}{ BMI cut off } & \multicolumn{2}{|c|}{ PSP_C } & \multicolumn{2}{|c|}{ Paces_P } & \multicolumn{2}{|c|}{ Paces_N } \\
\hline & $\mathbf{M}$ & SD & $\mathbf{M}$ & SD & $\mathbf{M}$ & SD \\
\hline $\mathrm{Nw}$ & 18.81 & 3.63 & 38.37 & 7.79 & 8.86 & 3.84 \\
\hline Ow & 18.42 & 3.39 & 38.38 & 7.40 & 8.97 & 3.72 \\
\hline $\mathrm{Ob}$ & 17.73 & 3.55 & 38.07 & 8.10 & 9.18 & 4.15 \\
\hline
\end{tabular}

Note: PSP_C refers to Physical self efficacy; PACES_P refers to the positive scale of the PACES questionnaire, and PACES_N to the negative scale of the PACES questionnaire.

Table 4. 2015/2016 years measures distribution-female.

\begin{tabular}{cccccc}
\hline \multicolumn{5}{c}{ Deciles-Female } \\
\hline Deciles & SLJ & MBT & $10 \times 4(\mathrm{~s})$ & wt6 $(\mathrm{m})$ & Motor coordination (s) \\
\hline MIN & 0.30 & 1.00 & 0.65 & 0.00 & 10.30 \\
1 decile & 0.94 & 3.50 & 12.00 & 510.00 & 17.61 \\
2 decile & 1.00 & 3.91 & 12.60 & 572.00 & 19.00 \\
3 decile & 1.00 & 4.00 & 13.00 & 600.00 & 20.00 \\
4 decile & 1.05 & 4.20 & 13.30 & 632.00 & 21.00 \\
5 decile & 1.20 & 4.68 & 13.60 & 659.00 & 21.87 \\
6 decile & 1.25 & 5.00 & 14.00 & 685.00 & 22.70 \\
7 decile & 1.30 & 5.34 & 14.30 & 710.00 & 23.82 \\
8 decile & 1.39 & 5.80 & 14.84 & 750.00 & 25.20 \\
9 decile & 1.50 & 6.30 & 15.60 & 805.00 & 27.25 \\
MAX & 1.70 & 6.50 & 52.40 & 1440.00 & 83.00 \\
\hline
\end{tabular}

Table 5. 2015/2016 years measures distribution-male.

\begin{tabular}{cccccc}
\hline \multicolumn{5}{c}{ Deciles-Male } \\
\hline Deciles & SLJ & MBT & $10 \times 4(\mathrm{~s})$ & wt6 $(\mathrm{m})$ & Motor coordination $(\mathrm{s})$ \\
\hline & 0.20 & 0.00 & 1.00 & 0.00 & 0.90 \\
\hline
\end{tabular}


Continued

\begin{tabular}{llllll}
\hline 1 decile & 1.00 & 3.98 & 11.50 & 512.00 & 16.70 \\
2 decile & 1.00 & 4.01 & 12.00 & 580.00 & 18.00 \\
3 decile & 1.20 & 4.70 & 12.40 & 619.00 & 19.00 \\
4 decile & 1.25 & 5.05 & 12.70 & 650.00 & 19.80 \\
5 decile & 1.30 & 5.42 & 13.00 & 680.00 & 20.76 \\
6 decile & 1.38 & 5.80 & 13.40 & 702.00 & 21.60 \\
7 decile & 1.44 & 6.06 & 13.80 & 735.00 & 22.60 \\
8 decile & 1.51 & 6.50 & 14.20 & 780.00 & 24.00 \\
9 decile & 1.63 & 7.12 & 15.10 & 840.90 & 26.30 \\
Max & 1.83 & 7.30 & 56.70 & 1565.00 & 83.60
\end{tabular}

has $50 \%$ of the cases below and $50 \%$ of the above. The results show that the values of the male 5th decile are higher than those of the girls in all the motor tests. It is reasonable to think that girls have lower motor performance than boys.

\section{Conclusion}

The monitoring of the SBAM program has confirmed previous studies highlighting that obese and overweight children have lower motor performance than normal-weight peers, especially in motor tasks required the horizontal and vertical displacement of the body (D'Hondt et al., 2009; Okely, Booth, \& Chey, 2004). Furthermore, perceived self-efficacy and enjoyment are related to motor development and the motor experience opportunity at school.

Lopes et al. (2012) proposed a model of negative correlations between BMI and gross motor coordination level considering the different ages; D'Hondt et al. (2009) studied the longitudinal evolution of gross motor coordination (in two years) highlighting a strong relation with BMI. As stated by previous studies, Cattuzzo et al. (2016) in a review show that the levels of mastery of motor skills are inversely proportional to body weight (27 studies out of 33). The perceived self-efficacy and enjoyment are related to motor development and BMI, as factors of mediation to promote motor activities even after school hours (Khodaverdi et al., 2015). These factors determine the times and methods of learning motor skills and are conditioned by the choice of teaching styles. A recent study (Utesch et al., 2018) has shown that children with higher levels of motor competence and self-perception show greater physical activity. Children who perceive their motor skills more accurately show higher levels of physical activity at different ages.

The perceived efficacy convictions, through the execution of motor skills, are determinant in the motor learning process as well as for the future practice of physical and sports activities (Feltz et al., 2008). According to Harter et al. (1978), engagement in physical activity contributes to generating the child's perception of his own competence and this, in turn, influences the child's persistence in 
performing a motor task and participating in motor activities.

This perception of motor competence derives directly from the concrete body-to-motor experience and the tests for assessing motor skills and abilities exert a direct influence on the child's future commitment in play, physical education and sport.

The influence of physical activity on self-perception is mediated by the type of activity, with positive effects associated with aerobic activity, aerobic activities associated with joint strength/mobility activities, dance, increasing intrinsic motivations towards the physical activity (Strong et al., 2005).

The study indicates that an accurate self-perception of motor competence can promote future physical activity. Therefore, the promotion of effective motor skills should be linked to the related development of perceived self-efficacy. Physical education at school offers all children various fun opportunities to increase daily and weekly physical activity levels, regular opportunities for motor learning and development, and social interactions. Some research priorities emerge to develop effective and sustainable interventions to increase the physical activity of children in the medium to long term; implement policies aimed at determining environmental changes to influence children's habits; implement longitudinal and transversal studies on motor activities performed by children and sedentary habits.

Physical activity, physical education and sport are areas of intervention that guide measures to promote public health; it is essential to analyze data related to the evolution and changes in motor skills and abilities and related factors.

To promote health education and effectively impact the sedentary habits of primary school children, it is extremely important to develop multi-component programs to promote physical education and motor activities.

The multi-component and interdisciplinary programs for the promotion of motor activities for children require economic investments and the availability of high-profile human resources: the school becomes the confluence of different professionals and Pedagogy and Teaching are also entrusted with task of connecting operations beyond that of searching for meanings and values.

The motor monitoring will allow the start of a regional observatory on motor development, the levels of physical activity and the correlated factors in developmental age, in order to establish a territorial-regional data bank useful for transversal and longitudinal analyzes, for studies on determinant motor and sports activities and systematically available for an integrated reading between different institutions (school, sport, health, urban planning).

\subsection{Limitations of the Study}

The limits of the study concern 1) the implementation of a systematic joint training course of the specialist and generalist teacher on the contents and methodologies of the various educational actions (sub-programs); 2) compliance with the schedule for monitoring, reducing the possibility of errors in data col- 
lection; 3) the synergistic action of the family in the training process; 4) promotion, integration and synergies with other projects taking place in the same school/territory.

By overcoming these limitations, the school setting becomes unavoidable for the promotion of health and to become a privileged environment in which to better appreciate the quality of teaching-learning of physical education.

\subsection{Future Development of the Study}

The monitoring results stimulate systematic and multi-component teaching interventions, curricular and extra-curricular, in collaboration with the family and other educational agencies of the territory.

The monitoring of motor abilities and related factors is a modality of study of the training process carried out and, through data analysis, a modality of implementation of the regional observatory on motor development of the child. The results are a first data bank for the realization of the regional observatory that will allow, subsequently, to study and compare the processes and the results of the interventions carried out on the territory. The data will be systematically analyzed and further enriched to become quality indicators of subsequent programs and actions.

\section{Conflicts of Interest}

The authors declare no conflicts of interest regarding the publication of this paper.

\section{References}

Beets, M. W., Okely, A., Weaver, R. G., Webster, C., Lubans, D., Brusseau, T., Cliff, D. P. et al. (2016). The Theory of Expanded, Extended, and Enhanced Opportunities for Youth Physical Activity Promotion. International Journal of Behavioral Nutrition and Physical Activity, 13, 120. https://doi.org/10.1186/s12966-016-0442-2

Carraro, A., Young, M. C., \&Robazza, C. (2008). A Contribution to the Validation of the Physical Activity Enjoyment Scale in an Italian Sample. Social Behavior and Personality: An International Journal, 36, 911-918. https://doi.org/10.2224/sbp.2008.36.7.911

Cattuzzo, M. T., dos Santos Henrique, R., Ré, A. H. N., de Oliveira, I. S., Melo, B. M., de Sousa Moura, M., Stodden, D. et al. (2016). Motor Competence and Health Related Physical Fitness in Youth: A Systematic Review. Journal of Science and Medicine in Sport, 19, 123-129. https://doi.org/10.1016/j.jsams.2014.12.004

Ciotto, C. M., \& Fede, M. H. (2014). PASS: Creating Physically Active School Systems. Journal of Physical Education, Recreation \& Dance, 85, 13-19. https://doi.org/10.1080/07303084.2014.946191

Cole, T. J. (2000). Establishing a Standard Definition for Child Overweight and Obesity Worldwide: International Survey. BMJ, 320, 1240-1240. https://doi.org/10.1136/bmj.320.7244.1240

Colella, D. (2014). Physical Education in Primary School in Italy. The Sbam! Program for the Promotion of Physically Active Lifestyles. In C. Scheuer, \& B. Antala (Eds.), Physical Education: Quality in Management and Teaching (pp. 121-134). Berlin: Logos VerlagBerlin GmbH. 
Colella, D., Morano, M., Bortoli, L., \& Robazza, C. (2008). A Physical Self Efficacy Scale for Children. Social Behavior and Personality: An International Journal, 36, 841-848. https://doi.org/10.2224/sbp.2008.36.6.841

D’Hondt, E., Deforche, B., De Bourdeaudhuij, I., \& Lenoir, M. (2009). Relationship between Motor Skill and Body Mass Index in 5- to 10-Year-Old Children. Adapted Physical Activity Quarterly, 26, 21-37. https://doi.org/10.1123/apaq.26.1.21

Ekelund, U. (2012). Moderate to Vigorous Physical Activity and Sedentary Time and Cardiometabolic Risk Factors in Children and Adolescents. JAMA, 307, 704. https://doi.org/10.1001/jama.2012.156

Feltz, D. L., Short, S., \& Sullivan, P. (2008). Self-Efficacy in Sport. Research and Strategies for Working with Athletes, Teams, and Coaches. Champaign, IL: Human Kinetics.

Harter, S. (1978). Effectance Motivation Reconsidered: Toward a Developmental Model. Human Development, 21, 34-64. https://doi.org/10.1159/000271574

Hillman, C. H., \& Biggan, J. R. (2017). A Review of Childhood Physical Activity, Brain, and Cognition: Perspectives on the Future. Pediatric Exercise Science, 29, 170-176.

https://doi.org/10.1123/pes.2016-0125

Hills, A. P., Dengel, D. R., \& Lubans, D. R. (2015). Supporting Public Health Priorities: Recommendations for Physical Education and Physical Activity Promotion in Schools. Progress in Cardiovascular Diseases, 57, 368-374.

https://doi.org/10.1016/j.pcad.2014.09.010

Khodaverdi, Z., Bahram, A., Stodden, D., \& Kazemnejad, A. (2015). The Relationship between Actual Motor Competence and Physical Activity in Children: Mediating Roles of Perceived Motor Competence and Health-Related Physical Fitness. Journal of Sports Sciences, 34, 1523-1529. https://doi.org/10.1080/02640414.2015.1122202

Lopes, V. P., Stodden, D. F., Bianchi, M. M., Maia, J. A. R., \& Rodrigues, L. P. (2012). Correlation between BMI and Motor Coordination in Children. Journal of Science and Medicine in Sport, 15, 38-43. https://doi.org/10.1016/j.jsams.2011.07.005

Lubans, D., Richards, J., Hillman, C., Faulkner, G., Beauchamp, M., Nilsson, M., Biddle, S. et al. (2016). Physical Activity for Cognitive and Mental Health in Youth: A Systematic Review of Mechanisms. Pediatrics, 138, e20161642.

https://doi.org/10.1542/peds.2016-1642

Malina, R. M. (2004). Motor Development during Infancy and Early Childhood: Overview and Suggested Directions for Research. International Journal of Sport and Health Science, 2, 50-66. https://doi.org/10.5432/ijshs.2.50

Okely, A. D., Booth, M. L., \& Chey, T. (2004). Relationships between Body Composition and Fundamental Movement Skills among Children and Adolescents. Research Quarterly for Exercise and Sport, 75, 238-247. https://doi.org/10.1080/02701367.2004.10609157

Pesce, C., Crova, C., Cereatti, L., Casella, R., \& Bellucci, M. (2009). Physical Activity and Mental Performance in Preadolescents: Effects of Acute Exercise on Free-Recall Memory. Mental Health and Physical Activity, 2, 16-22. https://doi.org/10.1016/j.mhpa.2009.02.001

Rauner, A., Mess, F., \& Woll, A. (2013). The Relationship between Physical Activity, Physical Fitness and Overweight in Adolescents: A Systematic Review of Studies Published in or after 2000. BMC Pediatrics, 13, 19.

https://doi.org/10.1186/1471-2431-13-19

Ruiz, J. R., Castro-Pinero, J., Espana-Romero, V., Artero, E. G., Ortega, F. B., Cuenca, M. M., Castillo, M. J. et al. (2010). Field-Based Fitness Assessment in Young People: The 
ALPHA Health-Related Fitness Test Battery for Children and Adolescents. British Journal of Sports Medicine, 45, 518-524. https://doi.org/10.1136/bjsm.2010.075341

Singh, A. (2012). Physical Activity and Performance at School. Archives of Pediatrics \& Adolescent Medicine, 166, 49. https://doi.org/10.1001/archpediatrics.2011.716

Strong, W. B., Malina, R. M., Cameron, J. R., Blimkie, C. J., Daniels, S. R., Dishman, R. K., Gutin, B., Hergenroeder, A. C., Must, A., Nixon, P. A., Pivarnik, J. M., Roland, T., Trost, S., Trudeau, F. et al. (2005). Evidence Based Physical Activity for School-Age Youth. Journal Pediatrics, 146, 732-737. https://doi.org/10.1016/j.jpeds.2005.01.055

Council of the European Union (2013). Recommendations Council of 26 November 2013 on Promoting Health-Enhancing Physical Activity across Sectors. Official Journal of the European Union, C354, 1-5.

http://eur-lex.europa.eu/legal-content/EN/ALL/?uri=OJ:C:2013:354:TOC

Utesch, T., Dreiskämper, D., Naul, R., \& Geukes, K. (2018). Understanding Physical (in-) Activity, Overweight, and Obesity in Childhood: Effects of Congruence between Physical Self-Concept and Motor Competence. Scientific Reports, 8, Article No. 5908.

https://doi.org/10.1038/s41598-018-24139-y 